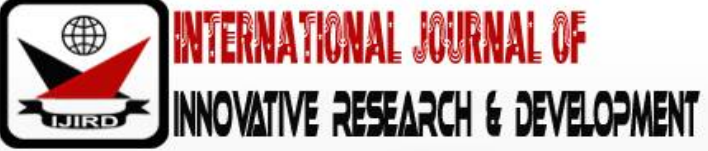

ISSN 2278 - 0211 (Online)

\section{Teachers' Familiarity and Opinion on Utilization of Narrative Recollection Technique in Basic Schools in Nigeria}

\author{
Dr. Adeleke, Ayobami Gideon \\ Senior Lecturer, Institute of Education, Obafemi Awolowo University, Nigeria
}

\begin{abstract}
:
Narration, as instructional strategy, is relegated to folktales and moonlight stories. It is duly unpopular in modern classroom situations hence narrative recollection is at oblivion. Since no educational system can rise above its teachers, this study dug into the extent of familiarity of teachers with narrative recollection as an instructional strategy. It also conducted an opinion poll on teacher's usage of narrative recollection technique (NRT). In a survey involving 10,752 teachers across five southwest states of Nigeria, the study found high level of familiarity with NRT in practicing teachers (68\%). The teachers indicated relevancy of the strategy to the school curriculum (66\%) and usefulness in the classroom (84\%). Respondents indicated impressive agreement ( $82 \%$ ) to usability of NRT. This is substantiated with elated values including making lesson's practical, stimulating thinking, improving narration skills, help detection of children with learning challenges and, its satiric appeal to real life situation. The study concludes that Nigerian teachers are familiar with and exposed to narrative recollection as instructional technique during pre-service trainings. Nigerian teachers vividly opine to the usage of narrative recollection as an instructional strategy. Since narrative recollection technique is found to be learner centered and transfers learning from passivity to activity, the study recommends narrative capability to improve self expression in learners; assistance in sorting out newly gained ideas; its applicability to cultural values taught and orientation of the society; among others, should be explored for its benefits.
\end{abstract}

Keywords: Narration, recollection, narrative recollection technique, satiric, narration skill

\section{Introduction}

Narration is a part of human nature as reasoning creatures. It is a tool for expressing ideas, persuading others and to understand the world. Narratives incorporate temporality, a social context, complicating events, and an evaluative conclusion that together make a coherent story (McAlpine, 2016). In history, societies have taught key principles through narrative recollections such that people paint on walls or rocks to express adoration toward divinities or deliver information. Recently, narrations are found in various literary works, discourses, personal and commercial advertisements and events. A narrative is a story which presents events in the logical and chronological sequence of occurrence over a time period with a view to instruct. Narrative recollection seeks to find the link between experience and present by analyzing and evaluating the satiric parts of the narration. Fisher (1984) viewed man as rhetorical creature from the point of view that, reasoning necessarily needs not be argumentative or implicative structured but in some kinds of symbolic action that are both non-discursive and discursive.

Narration has long found its way into education. According to Andrews, Hull and Donahue (2009), four main types of narrative techniques are being used for teaching. Stories are used to convince the learning audience and educate them; through narration, learners express their views, sort what they have gained, and explore new knowledge. Narrations are loved by all regardless of age, background and gender. They are easy on the mind, quite entertaining and inoffensive at teaching as individuals deduce and get instructed. This instructional method is referred to in other contexts as storytelling. According to Berger (1997) in Akinsanya and Bach (2014), a narrative is a story, and stories tell about things that have happened or are happening to people, animals, and aliens from outer space, etc. That is, a story contains a sequence of events, which means that narratives take place within or over some kind of time period. This time period can be very short, as in a nursery tale, or very long, as in some novels and epics. Akinsanya and Bach (2014) express narratives as very important in human culture as they tend to showcase the values being taught by our culture, and our culture as a whole, in a less formal and more enjoyable manner.

Narratives have been classified into various types including:

- Official Stories: Stories we learn from official sources e.g. church and school.

- Invented (Adapted) Stories: Stories created by people.

- Firsthand Stories: People's own experiences. These are the stories we talk about the most.

- Secondhand Stories: Firsthand stories of others that we have heard or remembered.

- Culturally Common Stories: These are stories gotten from our environment (Schank, 1990). 
The narrative can further be categorized by the mode of narration - written or spoken. The written narrative employs letterings, graphs and alphabetic coding to decipher and transfer information. These are mostly used in texts, books, reading materials, written instructions, presentations, responses to tests and examinations. Spoken narrative makes use of oral language which is naturally engaged in day-to-day activities, social relations and transactions.

Researchers have sought for significance of narratives in teaching-learning process and found that narrativebased instruction fixes the problem, the solution, and the learner - all within the context that the story frames (Cobley, 2001). The narrator controls all of the information received by the learner. Narratives, either fictional or non-fictional emotionally immerse the learner in the narrative's situation. Therefore, narratives are told mostly for entertainment's sake without pursuing an instructional objective. The under listed benefits can also be attributed to the use of narratives in educational settings:

- Establishes a pattern of creative life work;

- Improves social relations and group dynamics;

- Creates a flow - a sense of timeless expression and ongoing learning;

- It instills persuasiveness;

- Learning becomes technical and memory excellently aided;

- Engenders formulation of schematics in learners;

- Creates new sense of identity in learners whose shy background fades away;

- Equates experiences with backgrounds;

- Enhances growth and trust rapport development between teachers and learners;

- Learning is made engaging in lively atmosphere; and

- Exposure to literature and vocabulary development.

Recollection of information from memory is a lifelong, daily process. We are rarely conscious of how we recall information when we need it. In every learning procedure however, it is observable how participants narrate their experiences - some need extra time to reflect, some elaborate on interview questions yet, some use the dynamic visual method for recollection and describe how they mentally visualize the procedure. This mental copying of procedure is not surprising, as the current generation is very familiar with using video material in and outside the educational setting. The beauty in narrative-based instruction is its applicability both by teachers and learners as it fixes predicament, resolution, and the learner all within the context that the story frames (Cobley, 2001). It also persuades the learning audience and educate them yet allows learners to sort the content, express their views and explore new knowledge (Andrews et al, 2009).

Nigerian educational system has not changed very significantly from that handed down by the colonialists - the British. Most students are passive learners and teaching is done by transmission with emphasizes on memory over understanding and reproduction over application to real problems and creativity. Since most of the pre-service teacher training curricula are similarly designed, teachers are products of examination-driven curriculum with rote learning and memorization as the primary learning approaches. They were seldom asked and think in a critical way. An investigation into the relevance of narrative recollection as plausible instructional strategy is deemed necessary with the goal of encouraging reflection by in-service teachers towards helping Nigerian learners become self-directed and active learners. It is through the engaging learning process in relaxed atmosphere that learners can learn to be active agents in their own learning and transform what is learned through the screen of their own experience and existing understandings. This learning orientation might part teachers and learners from the rote mode of learning and give rise to substantial change and personal transformation that enable teachers and learners to become actively engaged in construction and reconstruction of knowledge for future practices.

\section{Theoretical Framew orks}

Research on narrative usage has a long history. Sigmund Freud (1911/ 1958) was said to use narratives primarily in applying his psychoanalytic theory to individual lives. Erik Erikson (1975) used the life history to explore how the historical moment influenced lives. Jerome Bruner (1991) acknowledged that personal meaning and reality are actually constructed during the making and telling of one's narratives. At a meeting of the American Psychological Association (APA, 1984), Bruner $(1987,1991)$ asserted that traditional logical-scientific mode of thought and a narrative mode of thought should be viewed as complementary and not supplementary and this is a challenge of the old positivism. He further claimed that the standards of positivism which dominated social sciences no longer remained unchallenged since there was no one framework but many. These assertions have sprouted modifications of views about narrative across many disciplines.

In education, Schwab was probably the first educational theorist signaling interest in the live experience of children and teachers in classrooms. His model of "the practical" curriculum inspired by the idea of Dewey, who "envisioned a dialogic view of curriculum development in which teacher would take part as practitioners fully knowledgeable about their students and about life and work in classroom" (Chan, 2012). Schwab offered a narrative of discovery and gave insight into why we needed to engage in collaborative inquiries attentive to the teacher perspectives and representative of reality expressed in teachers' term. Recently, many educators have used life stories and personal narratives as new ways of knowing in teaching and learning (Witherell \& Noddings, 1991; Clandinin \& Connelly, 1999; Miller, 2005; Craig, 2006). According to Clandinin and Connelly (1999), stories or narratives are "the closest we can come to experience". Carter (1993) also viewed teacher knowledge as being storied in nature and thus storytelling became a natural approach to understand what teachers knew. "Knowledge is rooted in experience and requires a form for its 
representation" (Eisner, 1988). Teachers' stories are therefore one of the most pervasive forms we can use to represent their experiences.

This study hereby seeks to determine Nigerian teacher's acquaintanceship with the narrative recollection technique (NRT) as a method of teaching. It also seeks teachers' opinions on the use of NRT.

\section{Methodology}

The research design adopted is descriptive survey. The totality of the teaching staff in Nigerian primary and secondary schools numbering about 700,000 (Adedigba, 2017) make the population. In-as-much as the complete coverage of the population is impossible and not economical, informed and effective decision demand for evidenced-based research. This is ascertained by the use of tables and calculators to heighten precision and the level of confidence thus, sampling and sample size determination were based on 0.05 confidence level (Martinez-Mesa, Gonzalez-Chica, Duquia, Bonamigo \& Bastos, 2016). Some 10,752 randomly selected teachers were sampled across primary, junior secondary and senior secondary schools in five convenience selected southwestern states of Nigeria. The respondents were randomly attracted into the study (demographic data in Table 1). A questionnaire titled Teachers Opinion on Narrative Techniques (TONT)', previously validated and found reliable in a pilot study in an eastern state (reliability index of 0.85 ) was instrumental to the study. Three graduate students who served as research assistants (recruited and trained) administered the instrument. Descriptive mean and percentages were used statistically in data analysis.

\begin{tabular}{|c|c|c|}
\hline \multicolumn{3}{|c|}{ Gender } \\
\hline \multicolumn{3}{|c|}{ Marital Status } \\
\hline Male & f & $\%$ \\
\hline Female & 3,815 & 53.96 \\
\hline Single & 6,068 & 35.5 \\
\hline Married & 869 & 56.4 \\
\hline Widowed & 2,103 \\
\hline Distribution to Schools / State \\
\hline State A & 19.51 \\
\hline \multicolumn{2}{|c|}{} \\
\hline State B & 2,294 & 21.24 \\
\hline State C & 2,027 & 18.77 \\
\hline State D & 2,231 & 20.66 \\
\hline State E & 2,140 & 19.8 \\
\hline \multicolumn{2}{|c|}{ Respondents Years in Service } \\
\hline $1-5$ & 83 & 0.77 \\
\hline $6-10$ & 3,082 & 28.66 \\
\hline $11-15$ & 2,658 & 24.72 \\
\hline $16-20$ & 3,072 & 28.57 \\
\hline $21-25$ & 1,460 & 13.58 \\
\hline Above 25 & 397 & 3.69 \\
\hline
\end{tabular}

Table 1: Demographic Data of Sampled Respondents

\section{Results and Discussions}

The thrust of this study is determining the familiarity of Nigerian teachers with the narrative recollection technique (NRT) as a method of teaching. This is important because the education system cannot perform any better than it invested in its teachers. Findings, as indicated in Table 2, revealed that narratives are being used in the teacher training curriculum. Sixty-eight (68\%) and twenty-four (24\%) percentages of respondents indicated high level familiarity and average familiarity with NRT respectively. The practicing teachers indicated that narratives are relevant to school children (72\%) as the school curriculum include topics that can be taught using NRT (66\%). Therefore, NRT is useful in the classroom (84\%) and found easier for learners' comprehension (90\%) and retention (88\%). The findings further indicate that NRT should not be jettisoned as an instructional technique as it might improve learning (68\%) if properly applied hence it seems inseparable from education curriculum especially at the primary schools (82\%).

This finding agrees with the studies of Sovia \& Afrineta (2017) which identified and explored narrative model in teaching of history in Indonesia. Narrative and drama models were viewed as creative methods that can be applied in the teaching and learning process so as to give positive effects on students and teachers in the subjects and phenomena they study. The models were found to be more participative and students interested in learning the history. Narrative was reported to increase students' perspective to be more responsive and aware of the history. Narrative and drama models also help students to improve their attitude to be more responsible, respectful, aware of their culture, tolerant, helpful, confident and faithful. In addition, the findings showed that narrative and drama could sometimes be integrated in different subjects and concluded that narrative is useful and applicable in learning activities. It is a powerful method that may be used to help students in understanding the lesson very well. Kukner and Orr (2013) have earlier investigated practitioners-based approach of narrative inquiry in teachers' education. They concluded that NRT offered teacher's educators, teachers and teacher candidates a sense of how they might draw upon a narrative framework to inform and 
inquire into their teaching practice and classroom curriculum. It can be concluded that the teacher's candidates exposed to this teaching technique tend to value and utilize it in the classroom hence; the familiarity of teachers with NRT is neither strange nor unexpected.

\begin{tabular}{|c|c|c|c|c|c|c|c|c|c|c|}
\hline \multirow[t]{2}{*}{ Items } & \multicolumn{2}{|c|}{ Very Well } & \multicolumn{2}{|c|}{ Average } & \multicolumn{2}{|c|}{ Partial } & \multicolumn{2}{|c|}{ Never } & \multicolumn{2}{|c|}{ Missing } \\
\hline & f & $\%$ & f & $\%$ & f & $\%$ & $\mathbf{f}$ & $\%$ & $\mathbf{f}$ & $\%$ \\
\hline $\begin{array}{l}\text { Narratives were used in my } \\
\text { training school(s). }\end{array}$ & 7312 & 68 & 2580 & 24 & 430 & 4 & 215 & 2 & 215 & 2 \\
\hline $\begin{array}{l}\text { The school curriculum } \\
\text { includes topics in narratives }\end{array}$ & 7096 & 66 & 3010 & 28 & 645 & 6 & 0 & 0 & & 0 \\
\hline $\begin{array}{c}\text { Narratives are relevant to } \\
\text { school children }\end{array}$ & 7741 & 72 & 1935 & 18 & 860 & 8 & 215 & 2 & 0 & 0 \\
\hline $\begin{array}{c}\text { Narratives are relevant in my } \\
\text { subject area }\end{array}$ & 5591 & 52 & 2795 & 26 & 1505 & 14 & 430 & 4 & 430 & 4 \\
\hline $\begin{array}{l}\text { I found narratives useful in } \\
\text { the classroom }\end{array}$ & 9031 & 84 & 1290 & 12 & 215 & 2 & 0 & 0 & 215 & 2 \\
\hline $\begin{array}{c}\text { Learners more easily } \\
\text { understand lessons taught in } \\
\text { narratives }\end{array}$ & 9677 & 90 & 1075 & 10 & 0 & 0 & 0 & 0 & 0 & 0 \\
\hline $\begin{array}{c}\text { Retention of lessons taught in } \\
\text { narratives are more than } \\
\text { ordinary }\end{array}$ & 9461 & 88 & 860 & 8 & 430 & 4 & 0 & 0 & 0 & 0 \\
\hline $\begin{array}{l}\text { Narrative recollection } \\
\text { technique might improve } \\
\text { learning in children }\end{array}$ & 7311 & 68 & 1290 & 12 & 1505 & 14 & 430 & 4 & 215 & 2 \\
\hline $\begin{array}{l}\text { Narratives are inseparable } \\
\text { from education curriculum } \\
\text { especially the primary. }\end{array}$ & 8817 & 82 & 1505 & 14 & 0 & 0 & 0 & 0 & 430 & 4 \\
\hline
\end{tabular}

Table 2: Teachers' Acquaintanceship with the NRT

The study also sought teachers' opinions on the use of narrative recollection technique (NRT) as a method of teaching in the teaching-learning process. Table 3 showed impressive agreement of respondents on the relevance of NRT to teaching across the school levels and its capability to aid retention or memory of learnt concepts (82\%). Teachers were of the opinion that narratives make lessons practical, stimulate thinking and narration skills in learners and its usage ease the detection of children with learning challenges (76\%). Results further opined that narratives influence learners' behavior $(66 \%)$ perhaps for its satiric nature.

Zuckerman (2007) opined that experimental schoolwork demonstrates how universal cognitive developmental transitions are produced in the classroom by changing teacher's orientation and teaching methods towards pupils' joint creativity. The development of children's motivation and initiative is the essential target. The teacher guides children's dialogues, mutual interaction and creativity aiming at creative solutions by introducing more complicated learning environments such as imagination, play orientation in order to wake up learning motivation and children's initiative. How much of such skills or tools are being used by in-service teachers' in the teaching process? This study harmonizes Zukerman's opinion and revealed impressive relevance of NRT to teaching across the school levels in Nigeria. The capability of NRT to aid retention or memory of learnt concepts (0.82) depicted teachers' construction of developmental trajectories in NRT to school learning (Table 3). In a recent research project on Construction of school mathematical knowledge: Discourse of teachers and teaching activity in Spain, Vanegas, Giménez and Samuel (2015) studied a group of future teachers of Early Childhood Education analyze implicit process of narratives on rich experiences in mathematical processes. The future teachers were able to identify many mathematical objects and some processes implicit in the narratives analyzed; give a limited value of the problem-solving process and more structured discourse, more connections, didactic arguments, recognition of a greater number of processes and more justifications. However, difficulties in recognizing the process of reasoning, testing and proof were noticed but this could be allayed by discussion and reflection on school experiences that allow future teachers to contrast school practices, different from those they have traditionally observed. 


\begin{tabular}{|c|c|c|c|c|c|c|c|c|c|c|}
\hline Items & \multicolumn{2}{|c|}{ Very Well } & \multicolumn{2}{|c|}{ Average } & \multicolumn{2}{c|}{ Partial } & \multicolumn{2}{c|}{ Never } & \multicolumn{2}{c|}{ Missing } \\
\cline { 2 - 12 } & $\mathbf{f}$ & $\mathbf{\%}$ & $\mathbf{f}$ & $\mathbf{\%}$ & $\mathbf{f}$ & $\mathbf{\%}$ & $\mathbf{f}$ & $\mathbf{\%}$ & $\mathbf{f}$ & $\mathbf{\%}$ \\
\hline $\begin{array}{c}\text { Narratives applicable in } \\
\text { answering questions }\end{array}$ & 5806 & 54 & 2580 & 24 & & 18 & 430 & 4 & 0 & 0 \\
\hline $\begin{array}{c}\text { Relevant to teaching in the } \\
\text { primaries }\end{array}$ & 8817 & 82 & 1076 & 10 & 430 & 4 & 215 & 2 & 215 & 2 \\
\hline Narratives make lessons practical & 8172 & 76 & 1505 & 14 & 1076 & 10 & 0 & 0 & 0 & 0 \\
\hline $\begin{array}{c}\text { Teachers are experienced with } \\
\text { narratives }\end{array}$ & 6451 & 60 & 3226 & 30 & 430 & 4 & 0 & 0 & 645 & 6 \\
\hline $\begin{array}{c}\text { Narratives stimulate learners } \\
\text { thinking, narration skill }\end{array}$ & 8172 & 76 & 1076 & 10 & 860 & 8 & 0 & 0 & 645 & 6 \\
\hline $\begin{array}{c}\text { Use of narratives influence } \\
\text { learner's behavior }\end{array}$ & 7096 & 66 & 1720 & 16 & 1290 & 12 & 215 & 2 & 430 & 4 \\
\hline $\begin{array}{c}\text { Useful in detecting learning } \\
\text { challenged }\end{array}$ & 8172 & 76 & 1505 & 14 & 645 & 6 & 0 & 0 & 430 & 4 \\
\hline $\begin{array}{c}\text { Narrative recollection is a } \\
\text { memory booster }\end{array}$ & 8817 & 82 & 1290 & 12 & 215 & 2 & 215 & 2 & 215 & 2 \\
\hline
\end{tabular}

Table 3: Teachers' Opinion on the use of NRT

The opinion of teachers was further reinforced in the utilization of NRT with or within other instructional methods. This item was meant to establish the viability of narrative recollection technique as dependent or otherwise on other teaching methods. Table 4 shows that narratives are mostly mixed with test and question designs, students' presentations and cooperative learning methods at 8.7, 6 and 5 percents respectively. These are relatively insignificant mix of NRT with the teaching methods tested for. The result thus indicates that NRT by itself stands as an instructional method though can be used within and in conjunction with other instructional designs. For example, Sovia and Afrineta (2017) explored narrative mixed with drama models as creative methods that can be applied in the teaching and learning process to give positive effects on learners. The models were participative and interesting in learning history. Garbett and Tynan (2007) asserted that storytelling recognizes narratives as the core of both human experiences and how we use those experiences to make meaning of the world. When discussing value as it relates to human interest and economics, one person's story about value becomes another person's story with subtle differences (Harris, 2007). This encourages recall of experiences with finances and gives color to topics that could otherwise seem impersonal and disconnected. In the view of Bishop and Kimball (2006), listening and telling stories help individuals understand themselves and others. The way learners relate experiences, and or respond to narrations is traceable to the story of their culture (Harris, 2007) hence; narrations can relay, synchronize and bridge gaps allowing students to connect their experiences, however limited, to the content of new lesson. To this end, a bridge of NRT with other teaching methods to aid teaching learning process is applauded.

\begin{tabular}{|c|c|c|}
\hline Teaching Methods & f & \% \\
\hline Students presentation & 642 & 6 \\
\hline Design thinking & 248 & 2.3 \\
\hline Self-learning & 257 & 2.4 \\
\hline Lecture method & 122 & 1 \\
\hline Social media & 204 & 2 \\
\hline Free online learning tools & 229 & 2.1 \\
\hline Direct instruction & 422 & 4 \\
\hline Cooperative learning & 527 & 5 \\
\hline Inquiry-based learning & 217 & 2 \\
\hline Test and question design & 938 & 8.7 \\
\hline
\end{tabular}

Table 4: Usage of NRT with Other

Teaching Methods

\section{Conclusion}

Narrative recollection technique is learner centered as it takes learning from passivity to activity. While school curricula in Nigeria still roll in the mire of rote and regurgitation, teachers as primary agents of change in the learning industry detects relevance of narrative recollection as plausible instructional strategy deemed necessary for self-directed, participatory, intuitive and active learning.

The study concludes that Nigerian teachers are familiar with narrative recollection as instructional technique having been exposed to it during pre-service trainings. It is also found in peculiar school curriculum for a few subjects. Importantly, NRT is relevant to the modern teaching-learning process.

Nigerian teachers vividly opine to the usage of narrative recollection as an instructional strategy. The expressive judgment of narrative's capability to improve self expression in learners; encourage exploration of new knowledge area, 
assist in sorting newly gained ideas and, its applicability to cultural values taught and orientation of the society among others stand overt.

The usability of NRT in teaching-learning process is justified by teachers' evidence of its relevance to the curriculum especially at the elementary levels. It is acclaimed to boost learners' memory, influence behavior via its satiric nature and, make detection of learning challenge easier and inoffensive.

\section{References}

i. Akinsanya, A. \& Bach, C. (2014). Narrative analysis: The Personal Experience Narrative Approach. ASEE 2014 Zone I Conference, April 3-5, University of Bridgeport, Bridgpeort, CT, USA.

ii. Andrews, D. H., Hull, T. D., \& Donahue, J. A. (2009). Storytelling as an instructional method:Descriptions and research questions. Interdisciplinary Journal of Problem-Based Learning, 3(2), 6- 23.

iii. Adedigba, A. (2017). Almost half of teachers in Nigerian schools not qualified - Registration Council. In Premium Times October 4, 2017.

iv. Berger, A. A. Narratives in Popular Culture, Media and Everyday Life. 1st ed. Thousand Oaks; London; New Delhi: Sage Publications, 1997.

v. Bishop, K. and Kimball, M. (2006). Engaging Students in Storytelling. Teacher Librarian,33(4), 31-38.

vi. Bruner, J. (1987). Life as Narrative. Social Research, 54 (1): 11-32.

vii. Bruner, J. (1991). The Narrative Construction of Reality. Critical Inquiry, 18, 1-21.

viii. Carter, K. (1993). The Place of story in the study of teaching and teacher education. Educational Researcher. 22(1): 5-12, 18.

ix. Chan, Esther Yim-mei (2012). The Transforming Power of Narrative in Teacher Education. Australian Journal of Teacher Education. 37 (3): 9

x. Clandinin, D. J., \& Connelly, F. M. (1999). Storying and restoring ourselves: Narrative and reflection. In A-Y Chen, \& J. Van Maanen (Eds.), The reflective spin: Case studies of teachers in higher education transforming action (pp. 1524). Farrer Road, Singapore: World Scientific.

xi. Cobley, P. (2001). Narrative. New York, NY: Routledge.

xii. Craig, C. (2006). Why is dissemination so difficult? The nature of teacher knowledge and thespread of curriculum reform. American Educational Research Journal, 43(2), 257-293.

xiii. Denning, S. (2009). What is a story? What is a narrative? Definitions. Retrieved from http:/ / www.stevedenning.com/ What_story.html

xiv. Eisner, E. W. (1988). The primacy of experience and the politics of method. EducationalResearcher, 17(5), 15-20.

xv. Fisher, W. (1984). Narration as a Human Communication Paradigm: The Case of Public Moral Argument. Communication Monographs. vol. 51: 1-23.

xvi. Garbett, D. and Tynan, B. (2007). Storytelling as a means of reflecting on the livedexperience of making curriculum in teacher education. Australian Journal of EarlyChildhood, 32(1), 47-51.

xvii. Harris, R. (2007). Blending Narratives: A Storytelling Strategy for Social Studies. SocialStudies 98(3), 111-115.

xviii. Kukner, J. M. \& Orr, A. M. (2013). Narrative Inquiry in the Teacher Education Classroom: A Review of Narrative Inquiries into Curriculum Making in Teacher Education. Teachers and Teaching Theory and Practice. 22 (1). http:/ / doi.org/ 10.1080/ 13540602.2013.780418

xix. Martinez-Mesa, J., Gonzalez-Chica, D. A., Duquia, R. P., Bonamigo, R. R. \& Bastos, J. L. (2016). Sampling: How to Select Participants in my Research Study? Anais Brasileiros de Dermatologia, 91 (3): 326-30. DOI: http:/ / dx.doi.org/ 10.1590/ abd1806-4841.20165254

xx. McAlpine, L. (2016). Why might you use narrative methodology? A story about narrative. Eesti Haridusteaduste Ajakiri, nr 4(1), pp. 32-57. doi: http:// dx.doi.org/ 10.12697/ eha.2016.4.1.02b

xxi. Miller, P. C. (2005). Narratives from the classroom: An introduction to teaching. ThousandOaks, CA: Sage Publications.

xxii. Schank, R. C. (1990). Tell Me A Story: A New Look at Real and Artificial Memory. Scribner, New York.

xxiii. Sovia, S. \& Afrineta, Y. (2017). Using Narrative and Drama Models in Teaching the History of Sukma Bangsa School (SBS). A Master's Thesis in Education submitted to School of Education, University of Tampere, Finland. Assessed 15-04-2018 at https:/ / tampub.uta.fi/ bitstream/ handle/ 10024/ 101859/ GRADU1503387262.pdf?sequence=1

xxiv. Vanegas, Y., Giménez, J. and Samuel, M. (2015). Discussing school mathematical narratives in early childhood future teacher education. https:/ / keynote.conference-services.net/ resources/ 444/ 5118/ pdf/ CERME10 0577.pdf

xxv. Witherell, C., \& Noddings, N. (1991). Stories lives tell: Narrative and dialogue in education. New York: Teachers College Press

xxvi. Zuckerman, G. (2007). How to supports children's initiatives? Journal of Russian and East European Psychology. Vol. 45 (3): 38-64. 